\title{
Demographics and vulnerability of a unique Australian fish, the weedy seadragon Phyllopteryx taeniolatus
}

\author{
Jaime Sanchez-Camara1 ${ }^{1}$, Keith Martin-Smith ${ }^{2}$, David J. Booth ${ }^{3}$, Juan Fritschi ${ }^{1}$, \\ Xavier Turon ${ }^{4, *}$ \\ ${ }^{1}$ Aquadec Aquariums S.L., 18600 Motril, Granada, Spain \\ ${ }^{2}$ Australian Antarctic Division, Australian Government Department of Environment, Water, Heritage and the Arts, \\ Kingston, Tasmania 7050, Australia \\ ${ }^{3}$ Department of Environmental Sciences, University of Technology, Sydney, PO Box 123, Broadway, Sydney, \\ New South Wales 2007, Australia \\ ${ }^{4}$ Department of Marine Ecology, Center for Advanced Studies of Blanes (CEAB, CSIC), 17300 Blanes (Girona), Spain
}

\begin{abstract}
The weedy seadragon Phyllopteryx taeniolatus is a vulnerable and endemic Australian fish and also an icon and flagship species for marine conservation. However, little is known about its population dynamics, which hinders the establishment of conservation policies. We have previously demonstrated seadragons to be highly site-attached, so we estimated population densities, growth and survival of weedy seadragons using mark-recapture techniques at 5 sites in New South Wales (NSW, $34^{\circ} \mathrm{S}$ ) and Tasmania (TAS, $43^{\circ} \mathrm{S}$ ), near the northern and southeastern limit of distribution for the species, over a 7 yr period. Population densities varied from ca. 10 to 70 seadragons ha ${ }^{-1}$ depending on site and year. There was a significant decline in the number of weedy seadragon sightings per unit area searched in 2 out of 3 study sites near Sydney, NSW, from 2001 to 2007 . There was also a decline at one of the 2 sites surveyed in the lower Derwent Estuary, TAS, in 2009 compared to 2003 and 2004. Survival rates at NSW sites ranged from 0.62 to $0.65 \mathrm{yr}^{-1}$ and were higher at TAS sites where they ranged from 0.71 to $0.77 \mathrm{yr}^{-1}$. Birth occurred approximately 3 mo later and seadragons exhibited significant slower growth in TAS (maximum adult size $\times$ growth rate parameter, $L_{\infty} \times k=31.02$ ) compared to NSW $\left(L_{\infty} \times k=55.15\right)$. This study is the first population assessment of seadragons over ecologically relevant spatial and temporal scales, and shows differences in the dynamics of populations at different latitudes. It also shows declines in some populations at widely separated sites. Determining whether these declines are natural interannual fluctuations or whether they are caused by environmental or habitat changes must be a priority for conservation.
\end{abstract}

KEY WORDS: Mark-recapture analyses · Conservation · Growth · Survival rate · Population dynamics · Endemic Australian fish

\section{INTRODUCTION}

In the world's oceans, human impacts have been substantial, leading to concerns about the extinction of marine taxa (Dulvy et al. 2003). These concerns have created the need to identify which species are at risk of extinction (Hutchings 2001, Dulvy et al. 2004) and design proper management strategies (Beissinger \& Westphal 1998, King \& Mcfarlane 2003). Extinction risk can be assessed based on knowledge of life history and ecology, examining changes in abundance, and using demographic analysis (Dulvy et al. 2004). Such assessment has been considerably aided by the use of individual tagging and monitoring. Burnham et al. (1987) and Lebreton et al. (1992) provide guidelines for capture-mark-recapture (CMR) data analysis and these methods are now generally used to estimate a wealth of demographic parameters such as abun- 
dance, recruitment, survival rates, immigration rates and population growth rates in fish, birds, mammals and amphibians. These demographic data are particularly important for flagship species, those used in conservation to raise public awareness, action and funding (Zacharias \& Roff 2001, Caro et al. 2004).

The syngnathid fish weedy seadragon Phyllopteryx taeniolatus is a flagship species restricted to the seaweed beds of southern Australia. They are popular and charismatic organisms due to their size, colorful appearance, and unusual life history characteristics including male brooding of eggs. However, the weedy seadragon might be a threatened species on its way to being endangered, because of its life history, including low fecundity and small home ranges (SanchezCamara \& Booth 2004, Sanchez-Camara et al. 2005), and due to its endemic nature. It might also be a good indicator of the condition of the habitat because of the dependence of seadragons on seaweed beds (Sanchez-Camara et al. 2006) and because they are highly sensitive to changes in temperature, salinity and water quality (Koldewey 2005). Although the species is well protected by legislation (Connolly 2006), the habitat of $P$. taeniolatus has been adversely affected by shoreline alterations and by pollution. The degradation is worst near major urban centers such as Sydney, raising concerns about the current state of seadragon populations (Connolly 2006). In Tasmania, the increase of sea urchins Centrostephanus rodgersii, due to harvesting of rock lobster and climate change, reduces the abundance of kelp and other macroalgae through the formation of urchin barrens (Ling \& Johnson 2009, Ling et al. 2009) and this reduction in macroalgae could adversely affect seadragons. The abundance of seadragons might have been affected by significant habitat degradation and loss in other areas of Australia as well. These concerns have led to a recent change in the status of $P$. taeniolatus in the IUCN Red List of Threatened species from Data Deficient to Near Threatened (Connolly 2006) which means that it is likely to qualify for a threatened category in the near future. In fact, it is precisely the lack of trend data that prevents seadragons from meeting any of the threatened categories.

Previous studies have provided data on the life history of Phyllopteryx taeniolatus, including population structure, site fidelity, movement patterns, reproductive ecology, recruitment and growth, habitat use and behaviour (Sanchez-Camara \& Booth 2004, SanchezCamara et al. 2005, 2006). However, these investigations were performed on the time frame of ca. $1 \mathrm{yr}$, which hindered the assessment of demographic trends. The aim of the present study was to build on previous results using longer term CMR data, collected from 2001 to 2009, and compare demographic charac- teristics between 2 widely separated locations. These findings should represent the basis for management policies in order to prevent this 'near threatened species' from becoming a truly endangered species.

\section{MATERIALS AND METHODS}

Study species. The weedy seadragon Phyllopteryx taeniolatus is a syngnathid fish endemic to southern Australian waters. It is found along much of the southern Australian coastline, from Port Stephens, New South Wales (NSW) $\left(32^{\circ} 38^{\prime} \mathrm{S}\right)$ southwards to Actaeon Island, Tasmania (TAS) $\left(43^{\circ} 32^{\prime} \mathrm{S}\right)$ and westwards through Victoria and South Australia to Geraldton, Western Australia (28 46' S) (Pogonoski et al. 2002). Weedy seadragons have elongate, non-prehensile tails and can grow up to $45 \mathrm{~cm}$ in length. Males are responsible for the offspring that they fertilize and incubate on the outside of the tail with each egg partly embedded in the skin (Kuiter 2000). They live among the larger algae on exposed reefs and feed mainly on mysid crustaceans (Edgar 2000).

Populations studied in NSW lived in resident groups throughout the year with males, females and juveniles occupying broadly overlapping home ranges. They breed from approximately June to January with a peak of brooding males at the end of the season. Males breed once or twice per breeding season with gestation periods of 30 to $38 \mathrm{~d}$ (Sanchez-Camara \& Booth 2004). Juvenile individuals appear in the residence areas from November to March measuring ca. $15 \mathrm{~cm}$ (Sanchez-Camara et al. 2005).

Study sites. Most of this study was carried out during 2004 and 2007 at 3 sites around Sydney, NSW

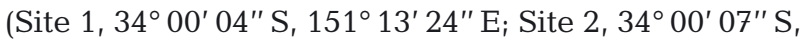

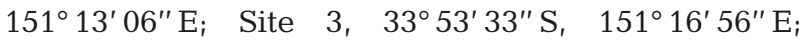
Fig. 1a,b). Previous studies were conducted in these same sites during 2001 and 2002 (see Sanchez-Camara $\&$ Booth 2004), and in the present study we take advantage of this previous information to analyze longerterm trends. Sites 1 and 2 are at Kurnell, in Botany Bay, an increasingly industrialized bay with Sydney's airport and major port facility on the shoreline. Potential threats to the kelp habitats and site water quality have come from construction and operation of a new desalination plant and several pipelines across nearby seagrass, as well as expansion of Australia's busiest seaport $5 \mathrm{~km}$ across Botany Bay. Site 3 is located in North Bondi, an exposed rocky reef only a few kilometers from the Sydney city centre. Additional occasional surveys were conducted around Sydney searching for tagged seadragons outside the tagging areas. In order to compare seadragon populations from different latitudinal ranges, fieldwork was also conducted in 2003, 


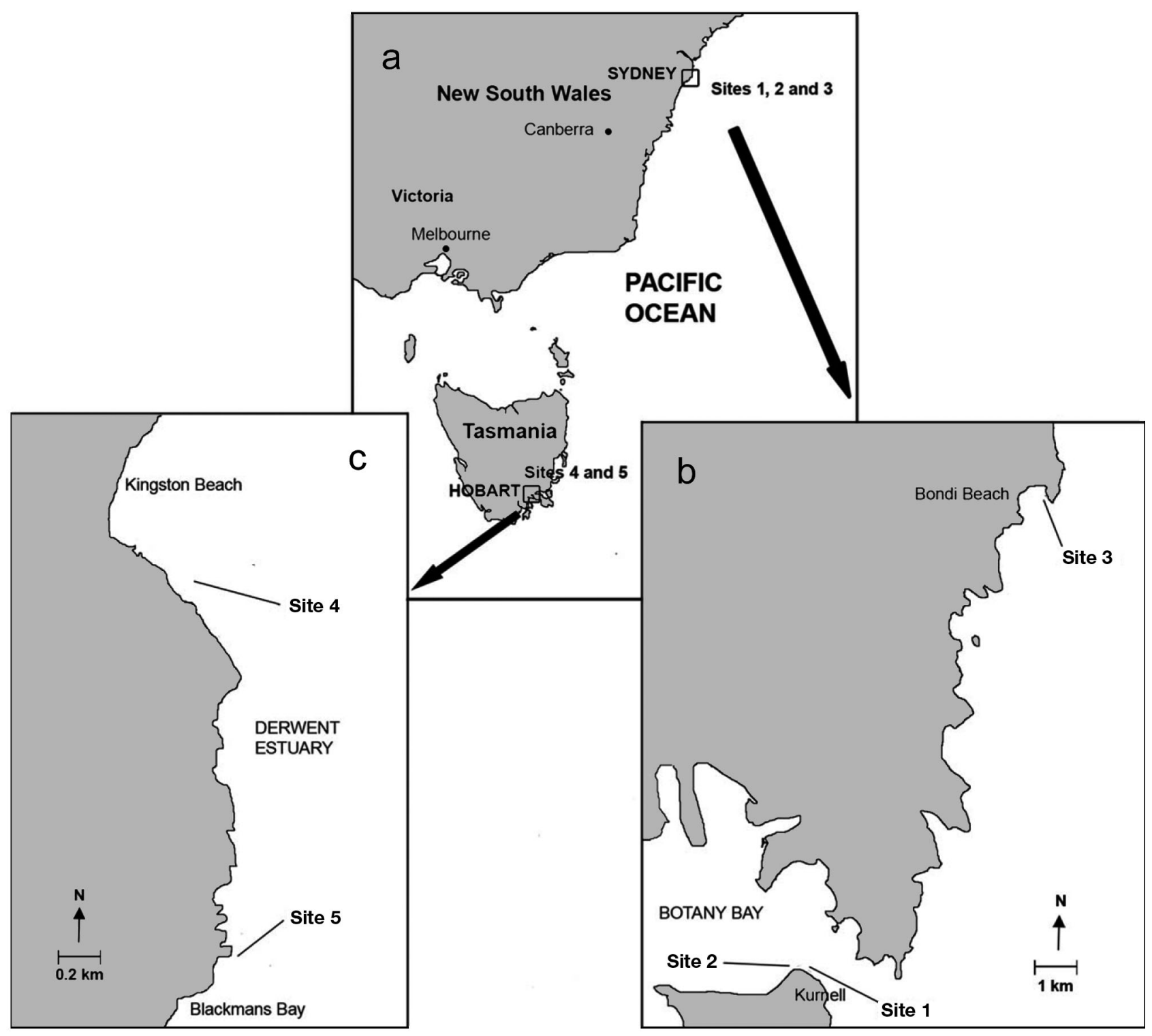

Fig. 1. Weedy seadragon study sites: (a) SE Australia, (b) New South Wales (NSW) sites, (c) Tasmanian (TAS) sites

2004 and 2009 in TAS, at Kingston Beach (Site 4, $\left.42^{\circ} 59^{\prime} 03^{\prime \prime} \mathrm{S}, 147^{\circ} 19^{\prime} 34^{\prime \prime} \mathrm{E}\right)$ and Blackman's Bay (Site 5, $43^{\circ} 00^{\prime} 02^{\prime \prime} \mathrm{S}, 147^{\circ} 19^{\prime} 41^{\prime \prime}$ E; Fig. 1a,c).

At Sites 1 to 3 we used permanent transects parallel to shore and $350 \mathrm{~m}$ in length, following the reef edge that were set up in the study of 2001 and 2002 (see Sanchez-Camara \& Booth 2004 for details). Estimated area covered was 1 ha for each site (see SanchezCamara et al. 2006). At Sites 4 and 5, transects parallel to the shore at the reef/sand interface were surveyed and site dimensions estimated using a GPS unit into a waterproof case that was towed on the surface. We covered an area similar in size to that of Sites 1 to 3 .
Sampling and tagging protocol. All tagging and observations were conducted using SCUBA (following Sanchez-Camara \& Booth 2004). On each dive at the NSW sites, the transect was followed from one end to the other with constant short incursions into the rocky reef and the sand flat. Seadragons were tagged with VIFE injectors (Visual Implant Fluorescent Elastomer®, Northwest Marine Technologies). The tagging was done in situ by gently restraining the animal with one hand and injecting the tagging material with the other. Additional individuals, especially recruits, were identified by their pattern of appendages, allowing estimation of recruitment and movement patterns. 
However, this method was not suitable for long-term study and these individuals were not considered in the mark-recapture analysis.

On each dive, sighted seadragons were checked for tags using an UV torch. Natural marks and appendages of all fish seen were noted to later corroborate tag identification and to avoid double-counting of untagged fish on the same dive. Seadragons were measured (standard length, $L_{\mathrm{s}}$ ) following SanchezCámara et al. (2005).

Data analyses. In the 3 NSW sites (1-3), we analyzed temporal changes in the number of sightings $\mathrm{ha}^{-1}$ made during each dive, assuming that the site area (transect width ca. $28 \mathrm{~m}$ ) was fully searched when covering the transect both ways, one way covering the kelp-sand limit and the other way covering the kelp area. The time spent on each survey was dependent on the level of complexity of the habitat, mainly related to kelp development, so we were confident that our ability to find seadragons was equivalent in the different sites and among years. We used ANOVA to compare the sightings per area of all surveys at each site using the different time periods as the categorical variable. To this end, we pooled data from 2001 to 2002 to allow homogeneous intervals between time points, and compared them to data from 2004 and from 2007. A 2-way ANOVA with time period and sex (male, female, juvenile, uncertain) as factors were also used to ascertain whether differences in time, if any, were consistent across sexes. For TAS, we pooled the data for 2003 to 2004 and compared the average number of sightings per area in this period with those of 2009 using a $t$-test.

Normality and homogeneity of variances of the data were assessed by Kolmogorov-Smirnov and Bartlett tests, respectively. When our untransformed data did not fulfill these assumptions (detailed in Results), rank transformed data were used in the analyses (Potvin \& Roff 1993). All analyses were performed with Sigmastat v3.1.

Population size estimates using the Schnabel and the Schumacher-Eschmeyer method (an extension of the Petersen estimator to a series of samples, based on the proportion of marked animals present in the sample) were calculated for the different sites and sample periods (Krebs 1999). This method assumes that the populations are closed over the time period concerned, which we considered a reasonable approximation over these relatively short time periods. These estimates were translated to density estimates by dividing by the area surveyed at each site. However, when there were few data, these estimates included large confidence intervals and in one case (Site 4, 2009, Schumacher-Eschmeyer method) it was impossible to reliably estimate density.

With the mark-recapture data we estimated apparent survival $(\phi)$ and encounter probability (p) of sea- dragons at each site using a Cormack-Jolly-Seber (CJS) model of open populations as implemented in program MARK (White \& Burnham 1999). The CJS model was chosen because, while the more general Jolly-Seber model can be used to estimate population size and the number of new individuals entering the population, it can be difficult to avoid bias in these estimates because of individual heterogeneity (White et al. 1982). Other models, including the robust design (Kendall et al. 1997), were investigated but the data structure of the encounter history matrix did not allow robust estimation of life history parameters. A set of candidate models were generated for each site including the full models (i.e. dependent on time and group), and reduced models with time and group-independent apparent survival $\phi($.$) and encounter probability \mathrm{p}($.$) ,$ time-dependent apparent survival $\phi(t)$ and encounter probability $\mathrm{p}(t)$ and group-specific (male, female, juvenile) apparent survival $\phi(g)$ and encounter probability $\mathrm{p}(\mathrm{g})$. Bootstrap goodness-of-fit tests were implemented with the MARK program. Where these tests indicated significant extra binomial variation, the variance inflation factor $\hat{c}$ was estimated and used to adjust the model outputs (see Cooch \& White 2010). The Akaike Information Criterion (AIC) for each model was compared to indicate the degree of support. The apparent survival and encounter probabilities were estimated for all models with model likelihoods $>0.20$ (Cooch \& White 2010).

We calculated a growth curve following the wellknown von Bertalanffy (VB) equation (von Bertalanffy 1938):

$$
L_{t}=L_{\infty}-\left(L_{\infty}-L_{0}\right) \times \mathrm{e}^{-k \cdot t}
$$

where $L_{t}$ is the size (in our case, standard length in $\mathrm{cm}$ ) of an individual of age $t(\mathrm{yr}), L_{\infty}$ is the maximal size attained at adulthood, $L_{0}$ is the size at birth and $k$ is a growth rate parameter. In a previous study (SanchezCamara et al. 2005) we provided a VB growth function calculated on data from recruits and juveniles at the NSW sites (1-3) during 2001 to 2002. Now we have gathered a larger dataset by considering all individuals that could be assigned to a given cohort in all sites over the study years, and including all measures available for them, so we have a larger number of individuals and a much longer temporal frame to estimate more accurately the parameters of the VB function. We calculated the growth functions for NSW and for TAS separately.

The VB function has 3 parameters $\left(L_{\infty}, L_{0}\right.$, and $\left.k\right)$. In addition, we need to estimate a date of birth to determine the exact age. The 4 parameters were estimated simultaneously for the NSW populations, for which we had more data; while for TAS some parameters had to be set to pre-established values to obtain reliable esti- 
mates for the remaining parameters (see Results). The growth function parameters that maximized the fit of our data to the equation were estimated using a nonlinear iterative procedure (NONLIN module of the program Systat v. 11 with least squares estimation and using a quasi-Newton algorithm).

\section{RESULTS}

\section{Population abundances and temporal trends}

Overall, 210 dives and 456 diving hours were performed across all sites and years. At NSW sites, number of dives each year $(2001,2002,2004,2007)$ were 40, 16, 22, 6 for Site 1, 22, 12, 22, 5 for Site 2 and 1, 10, 16,1 for Site 3 . At TAS sites, number of dives each year $(2003,2004,2009)$ were 5, 7, 5 for Site 4 and 1, 3, 16 for
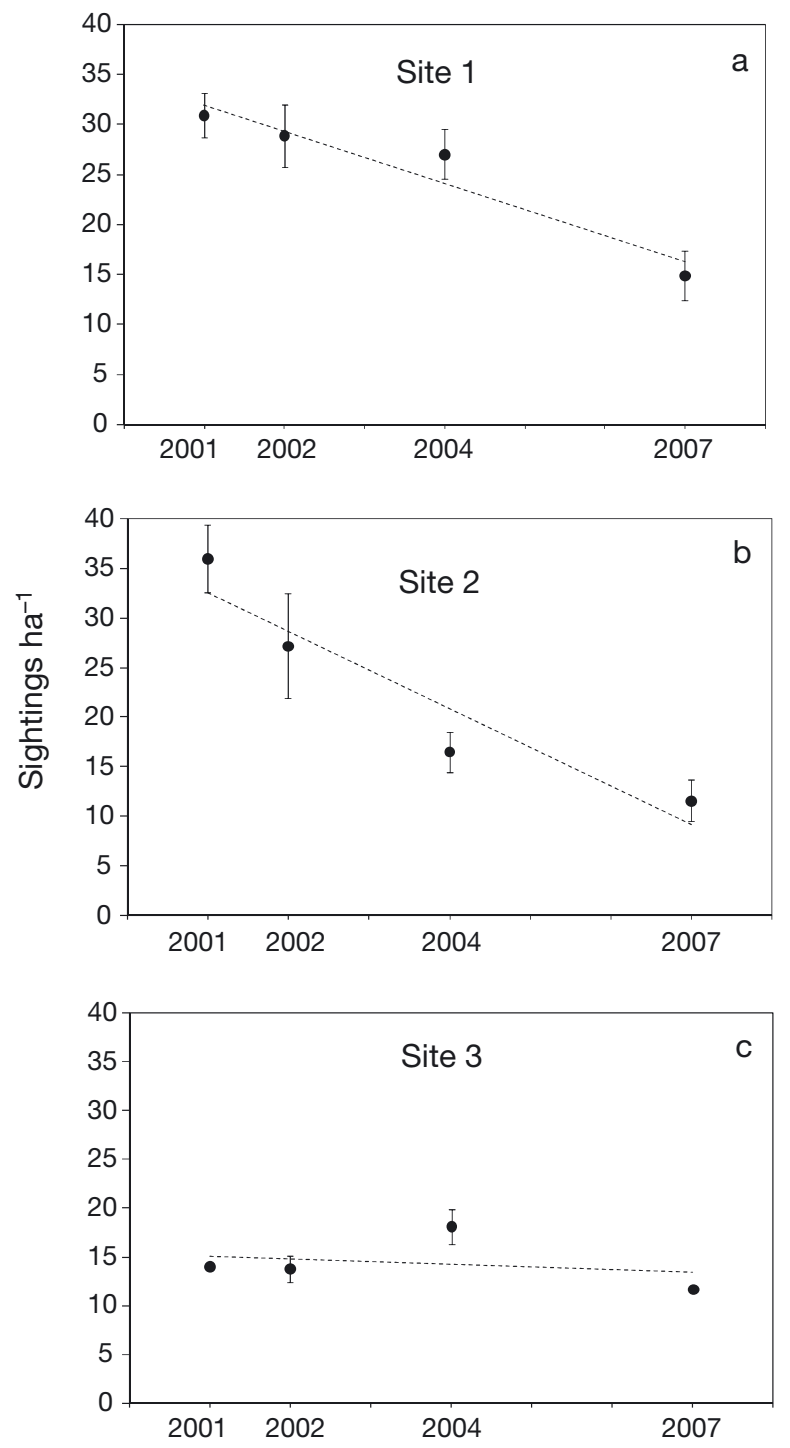

Site 5. Thirteen more dives and 25 diving hours were performed at the additional sites. A total of 223 seadragons were tagged from 2001 to 2009 at the study sites, 147 at the NSW sites and 76 at the TAS sites. Surveys reported 845 sightings of tagged individuals. Additionally, a number of recruits (settled young of the year) were individually identified by appendages due to the difficulty of tagging small specimens. The cohorts of those recruits will be identified with the notation Y00-01 (i.e. young from the season 2000 to 2001), Y01-02, etc. indicating the breeding season in which the animals were born.

There was a temporal trend across years of decreasing numbers of seadragons seen over the study at Sites 1, 2 and 4 (Fig. 2a,b,d) but not at Sites 3 and 5 (Fig. 2c,e). At Site 1, the ANOVA analyses showed a significant change over time $\left(F_{(2,76)}=6.973, \mathrm{p}=0.002\right.$, rank-transformed data). The post hoc comparisons
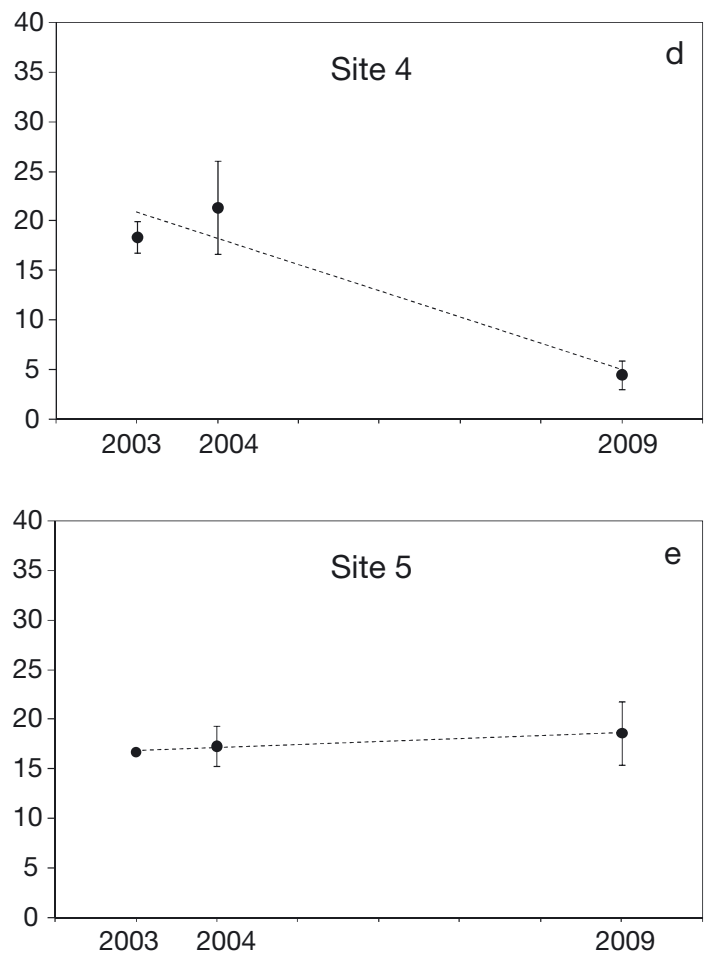

Fig. 2. Phyllopteryx taeniolatus. Weedy seadragon population trends (sightings ha ${ }^{-1}$ ) observed at sites in $(\mathrm{a}, \mathrm{b}, \mathrm{c})$ NSW and $(\mathrm{d}, \mathrm{e})$ TAS 
(SNK, Student-Newman-Keuls method) detected significant differences among all time periods except for the comparison 2001-02 vs. 2004. Similarly, at Site 2 the overall time period effect was significant $\left(F_{(2,56)}=\right.$ $12.642, \mathrm{p}<0.001$, rank-transformed data) and the SNK revealed that the only non-significant difference was between 2004 and 2007. In contrast, the time period did not have a significant effect on the number of sightings at Site $3\left(F_{(2,26)}=1.854, \mathrm{p}=0.177\right)$. Thus, a significant decline in population abundance was substantiated at Sites 1 and 2 in Botany Bay but not in the more exposed Site 3. At Tasmanian sites, there was a significant decline in numbers in 2009 compared to 2003 and 2004 at Site 4 (t-test: $t=3.504, \mathrm{df}=15, \mathrm{p}=0.003$ ) but not at Site 5 ( $t$-test: $t=-0.222, \mathrm{df}=18, \mathrm{p}=0.826$ ).

The number of males and females seen per area searched are shown for the 3 NSW sites (Fig. 3). A trend
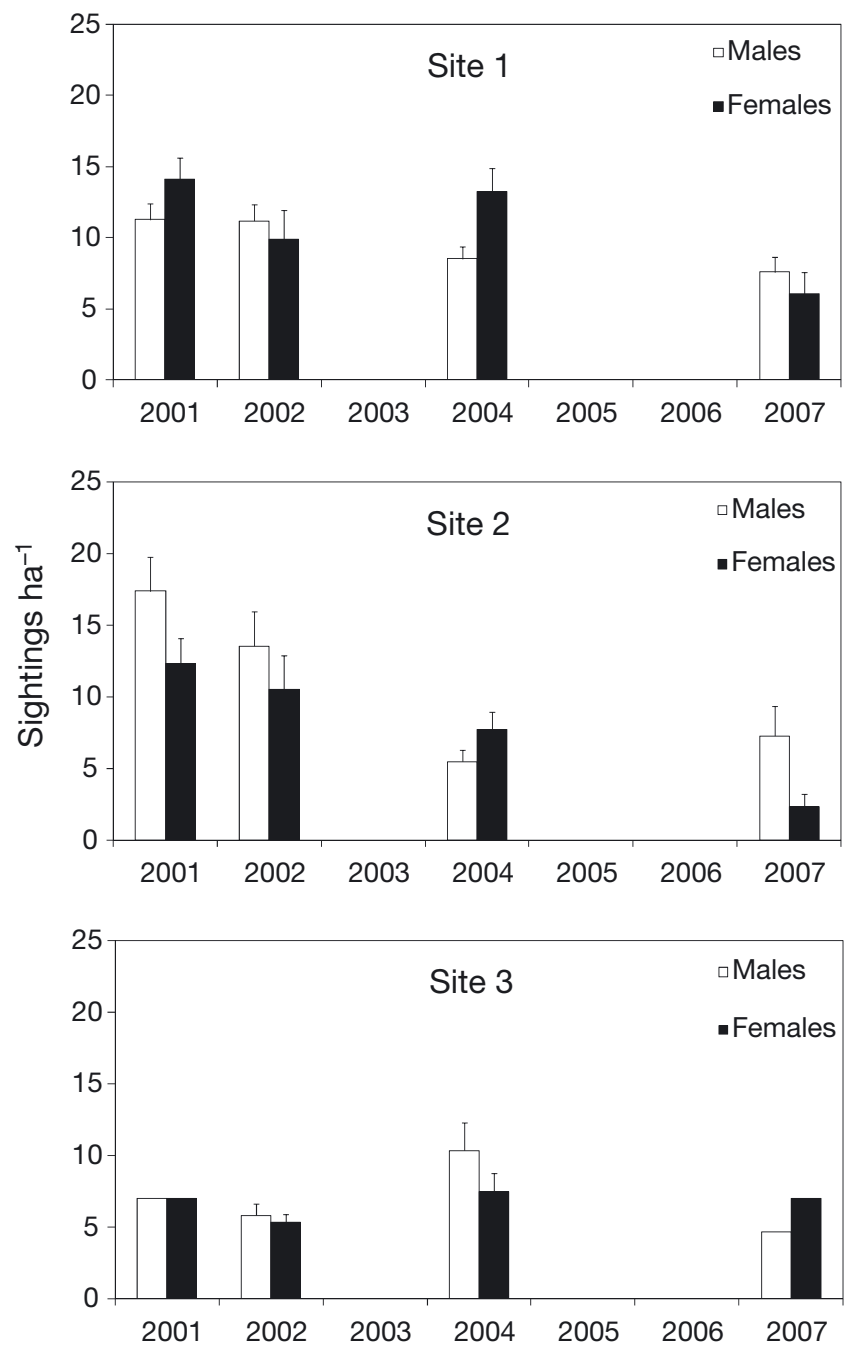

Fig. 3. Phyllopteryx taeniolatus. Annual average sightings of male and female weedy seadragons per area surveyed at Sites 1, 2 and 3 in NSW of decline in the number of males, but not of females, can be observed at Site 2. However, no significant interaction was found between year and sex (male, female, juvenile) (Site 1, $F_{(9,300)}=1.776, \mathrm{p}=0.072 ;$ Site $2, F_{(9,220)}$ $=1.810, \mathrm{p}=0.068$, rank-transformed data; Site $3, F_{(9,96)}$ $=1.1946, \mathrm{p}=0.308)$. The factor sex was significant at all 3 NSW sites (Site 1, $F_{(3,320)}=41.184, \mathrm{p}<0.001$; Site 2, $F_{(3,220)}=40.652, \mathrm{p}<0.001$; Site 3, $F_{(3,96)}=6.522, \mathrm{p}<$ $0.001)$; in all cases there were significantly fewer sightings of juveniles compared to males and females (SNK test). Due to the lower number of observations and the fact that the sex was not determined for some seadragons in 2003 and 2004, these analyses could not be done for Tasmanian sites.

Population estimates using the Schnabel and Schmacher-Eschmeyer methods are shown in Table 1. Similar trends in abundance over time to those found with the number of sightings were observed. At Site 1 the number of seadragons $\mathrm{ha}^{-1}$ decreased from 45-49 in 2001-02 (depending on the period and method used) to 30-34 in 2004-07. The same trend occurred at Site 2 , with seadragons per ha decreasing from ca. 56-69 in 2001-02 to 28-35 in 2004-07. At Site 3 estimated population sizes were 10 to 15 seadragons with no clear temporal trend between 2002 and 2004 when counts were made. At Site 4 estimated population sizes decreased from $32-34$ in 2003-04 to 27 in 2009. At Site 5 population estimates increased from 15 in 2004 to 32-34 in 2009 (Table 1).

\section{Survival and encounter rates}

Summaries of the most likely models explaining the patterns of mark-recapture are given in Table 2. At Site 1 the best supported model was $\phi(g) p(g)$, with higher apparent survival and lower encounter probabilities for juveniles compared to adults. Males had a slightly lower survival rate and probability of encounter compared to females. At Sites 2, 3 and 4 the best supported models were $\phi() p.($.$) , with no differences in$ apparent survival or encounter probabilities among any of the groups. At Site 5, both the $\phi(g) p($.$) , with$ potential differences in apparent survival between males and females, and $\phi() p.($.$) models were well sup-$ ported. We suggest that the model $\phi() p.($.) is the correct model for this site but that fewer marked animals and less diving effort compared to other sites biased the results. Apparent survival rates were higher for TAS sites (Site $4 \phi()=$.0.770 , Site $5 \phi()=$.0.713 ) than for NSW sites (Site 1, $\phi$ (female) $=0.577$; Site $1, \phi($ male $)=$ 0.473 ; Site 2, $\phi()=$.0.650 ; Site $3, \phi()=$.0.642 ) with the exception of the individuals tagged as juveniles in 2001 (Y00-01) at Site 1 (Site 1, $\phi$ (juvenile) $=0.822$ ). Encounter probabilities were higher at Site 3 com- 
Table 1. Phyllopteryx taeniolatus. Schnabel and Schmacher-Eschmeyer population size estimates (seadragons ha ${ }^{-1}$ ) at sites in New South Wales (NSW) and Tasmania (TAS). -: Estimate was unreliable (see 'Materials and methods: Data analyses')

\begin{tabular}{|lccccc|}
\hline \multirow{2}{*}{ Site } & \multirow{2}{*}{ Period } & \multicolumn{3}{c}{ Schnabel } & \multicolumn{2}{c}{ Schmacher-Eschmeyer } \\
\cline { 3 - 4 } 1 (NSW) & Jul-Dec 2001 & 45.4 & $39.5-53.5$ & 46.7 & $42.7-51.5$ \\
& Jan-Jun 2002 & 45.7 & $35.6-63.8$ & 48.9 & $39.7-63.7$ \\
& Mar-Apr 2004 & 31.1 & $22.9-45.9$ & 32.7 & $27.8-39.8$ \\
& Nov-Dec 2004 & 30.1 & $20.6-51.2$ & 32.1 & $24.4-46.8$ \\
& Nov-Dec 2007 & 32.7 & $15.3-75.0$ & 34.1 & $19.0-168.8$ \\
& & & & & \\
2 (NSW) & Jul-Dec 2001 & 69.3 & $52.5-101.9$ & 66.5 & $53.3-88.4$ \\
& Jan-Jun 2002 & 61.6 & $37.6-106.4$ & 55.8 & $34.7-141.5$ \\
& Mar-Apr 2004 & 32.4 & $20.5-60.0$ & 31.0 & $25.0-40.9$ \\
& Nov-Dec 2004 & 27.8 & $18.2-76.1$ & 34.6 & $18.8-215.0$ \\
& Nov-Dec 2007 & 34.0 & $14.2-99.6$ & 29.9 & $15.9-245.7$ \\
& & & & & \\
3 (NSW) & Jan-Jun 2002 & 9.7 & $7.1-13.7$ & 9.8 & $9.2-10.4$ \\
& Mar-Apr 2004 & 11.3 & $8.0-25.4$ & 11.9 & $7.5-29.0$ \\
& Nov-Dec 2004 & 14.1 & $9.2-23.9$ & 15.2 & $9.7-34.9$ \\
& & & & & \\
4 (TAS) & Sep-Nov 2003 & 33.7 & $19.9-60.4$ & 34.4 & $19.6-62.5$ \\
& Dec 2004 & 32.2 & $19.6-62.5$ & 33.7 & $20.7-91.3$ \\
& Mar-Oct 2009 & 27.0 & $8.1-152.1$ & - & - \\
& & & & & \\
5 (TAS) & Dec 2004 & 15.0 & $6.3-43.9$ & 15.0 & $10.1-29.4$ \\
& Feb-Dec 2009 & 32.4 & $24.0-46.9$ & 34.4 & $21.7-83.4$ \\
\hline
\end{tabular}

Table 2. Phyllopteryx taeniolatus. Estimates of apparent annual survival $(\phi)$ and encounter probabilities (p) for seadragons at the surveyed sites in NSW and TAS. (.): time- and group-independent value; $(\mathrm{g})$ : group-dependent value

\begin{tabular}{|c|c|c|c|c|c|c|}
\hline Site & Model & $\begin{array}{c}\mathrm{AIC}_{\mathrm{c}} \\
\text { weight }\end{array}$ & $\begin{array}{l}\text { Model } \\
\text { likeli- } \\
\text { hood }\end{array}$ & Parameter & Estimate & $\begin{array}{c}95 \% \\
\text { CI }\end{array}$ \\
\hline \multirow[t]{6}{*}{1 (NSW) } & $\phi(\mathrm{g}) \mathrm{p}(\mathrm{g})$ & 0.913 & 1 & $\phi($ female) & 0.577 & $0.425-0.702$ \\
\hline & & & & $\phi$ (male) & 0.473 & $0.292-0.633$ \\
\hline & & & & $\phi$ (juvenile) & 0.822 & $0.626-0.921$ \\
\hline & & & & $\mathrm{p}$ (female) & 0.212 & $0.186-0.241$ \\
\hline & & & & $\mathrm{p}$ (male) & 0.170 & $0.141-0.205$ \\
\hline & & & & p(juvenile) & 0.135 & $0.108-0.167$ \\
\hline \multirow[t]{2}{*}{2 (NSW) } & $\phi(.) \mathrm{p}()$. & 0.813 & 1 & $\phi()$. & 0.650 & $0.515-0.756$ \\
\hline & & & & $\mathrm{p}()$. & 0.111 & $0.092-0.133$ \\
\hline \multirow[t]{2}{*}{3 (NSW) } & $\phi(.) \mathrm{p}()$. & 0.699 & 1 & $\phi()$. & 0.642 & $0.445-0.785$ \\
\hline & & & & $\mathrm{p}()$. & 0.365 & $0.302-0.433$ \\
\hline \multirow[t]{2}{*}{4 (TAS) } & $\phi(.) \mathrm{p}()$. & 0.474 & 1 & $\phi()$. & 0.770 & $0.577-0.883$ \\
\hline & & & & $\mathrm{p}()$. & 0.189 & $0.137-0.255$ \\
\hline \multirow[t]{2}{*}{5 (TAS) } & $\phi(.) \mathrm{p}()$. & 0.330 & 0.786 & $\phi()$. & 0.713 & $0.474-0.858$ \\
\hline & & & & $\mathrm{p}()$. & 0.182 & $0.107-0.291$ \\
\hline
\end{tabular}

\section{Site fidelity and longevity}

Seadragons showed similar persistence at all sites. One third (33\%) of the seadragons tagged at Sites 1 and 2 (NSW) from July to November 2001 were seen in 2004. Of seadragons tagged at Site 4 (TAS) during 2003, $74 \%$ were seen in December 2004; however, none of the 7 individuals tagged at Site 5 in 2003 were seen again. Nevertheless, at least for young life-history stages, relocation to new sites cannot be dismissed; another seadragon initially tagged as a juvenile in 2001 at Site 1 and never seen there again was found at Bare Island $\left(33^{\circ} 59^{\prime} 29^{\prime \prime} \mathrm{S}, 151^{\circ} 13^{\prime} 46^{\prime \prime} \mathrm{E}, 1.3 \mathrm{~km}\right.$ away, on the other side of the bay) in December 2004. No other tagged seadragon was seen during the surveys made in the Sydney area outside the study sites.

There were considerable differences in persistence between males, females and juveniles in NSW. Of the Y00-01 juveniles initially tagged in 2001, $50 \%$ were later seen in November to December 2004, while this number decreased to $31 \%$ for females and only $7 \%$ for males (Fig. 4). These females and males were tagged in 2001 at over $33 \mathrm{~cm}$ in length and an expected age over 2 yr. Therefore, they were more than 5 yr old when they were subsequently observed in December 2004. However, none of the seadragons tagged in 2001, including the youngest ones (belonging to Y00-01 cohort), were seen in December 2007, despite the site fidelity exhibited from 2001 to 2004. This suggests that the longevity is ca. 6 yr for NSW seadragons.

At Tasmanian sites, 2 adults tagged in 2004 and 1 adult tagged in 2003 were encountered in 2009. The latter corresponds to the seadragon with the maximum period of time from the first encounter to the last in our study. It pared to the other sites likely because the better visibility and the lower density of the kelp bed facilitated seadragon sightings. Goodness-of-fit tests for the mark-recapture data revealed that there was no additional binomial variation due to transience at any of the sites $(p>0.20)$. was first seen on September 12, 2003 with a size of $31.5 \mathrm{~cm}$ and last seen on February 27, 2009. We are confident that the animal corresponded, at the latest, to the cohort Y00-01 because 2 smaller-size ageclasses could be identified in 2003 ranging from 26.0 to $29.6 \mathrm{~cm}$ (cohort Y01-02) and from 18.7 to $20.5 \mathrm{~cm}$ 


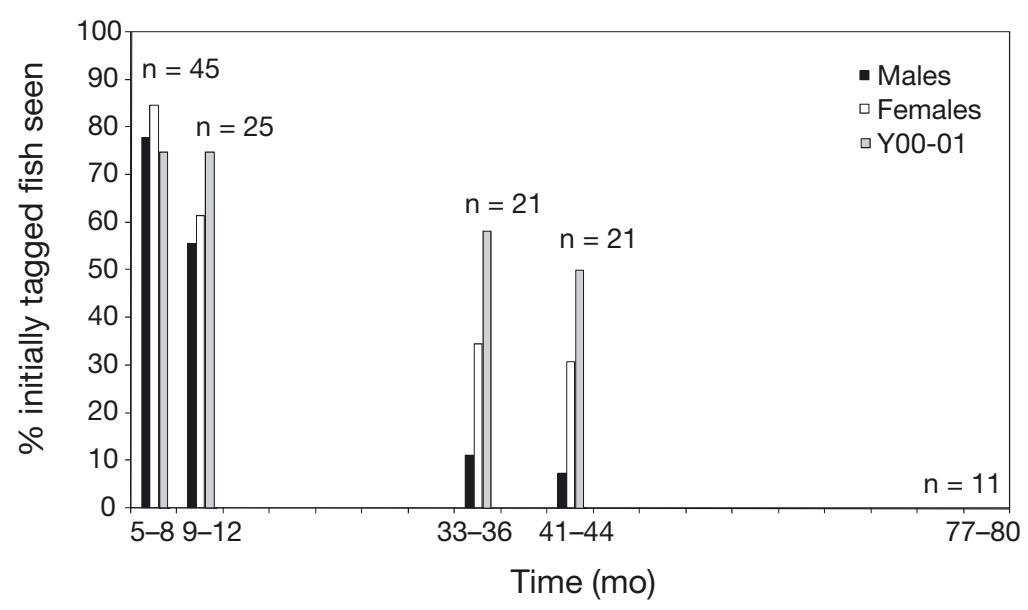

Fig. 4. Phyllopteryx taeniolatus. Percentage of initially-tagged seadragons (tagged from July to October 2001) seen over the study period at NSW sites. Time was divided in 4 mo blocks. Only those months in which surveys were conducted are indicated in the $x$-axis

(cohort Y02-03). Therefore, it is the oldest seadragon we can report in this study, with an estimated age over $8 \mathrm{yr}$.

\section{Growth}

Fifteen recruits from the breeding season Y00-01, 10 from Y01-02, 22 from Y03-04 and 1 from Y04-05 could be identified at the NSW sites. Two recruits from Y0102 and 4 from Y02-03 were also identified and measured at TAS sites. We used all measures made on these identified recruits in subsequent observations to estimate a growth curve (Fig. 5). In NSW the number of observations allowed us to make iterative estimates of all parameters simultaneously. Although the birth date

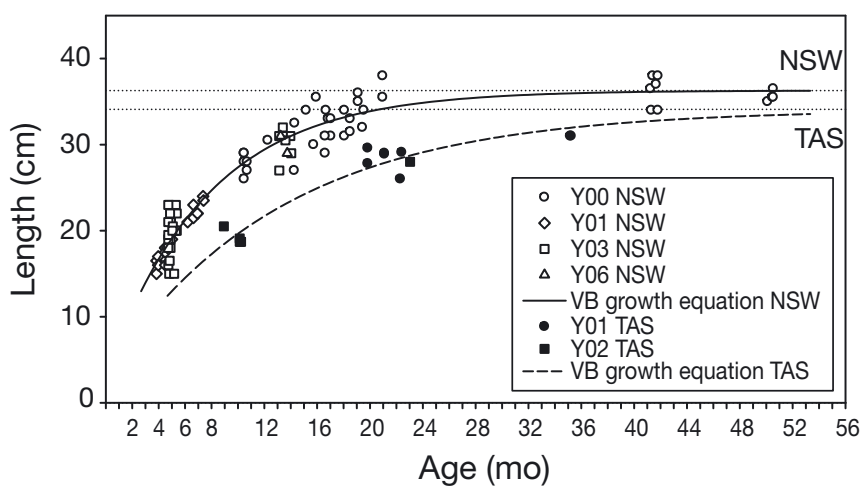

Fig. 5. Phyllopteryx taeniolatus. Standard lengths vs. age taken from identified young-of-the-year seadragons at sites near Sydney (NSW) and near Hobart (TAS). The inferred VB growth equations are also shown. Dotted lines: asymptotic maximum adult sizes likely varied among individuals and years, in order to be able to use all observations we had to include in the equation the estimate of a common birth date that maximized the fit of the growth function to the data. This estimate was that, on average, the seadragons in the Sydney area were born the 24 October. The estimate of the growth rate $k$ obtained was $1.52 \mathrm{yr}^{-1}$ (95\% CI $=1.27-1.78) ; L_{0}$ was estimated at $3.33 \mathrm{~cm}(0.087-6.57)$, and the $L_{\infty}$ estimate was $36.28 \mathrm{~cm}$ (35.15-37.42). The $\mathrm{r}^{2}$ of the regression was 0.936 . Thus, the VB growth curve obtained was:

$$
L_{t}=36.28-(36.28-3.33) \times \mathrm{e}^{(-1.52 \cdot t)}
$$

The value estimated for $L_{0}$ (size at birth) was reassuringly close to the $3.2 \mathrm{~cm}$ actually measured in aquarium by Forsgren \& Lowe (2006). The asymptotic size $\left(L_{\infty}\right)$, on the other hand, was almost coincident with the overall mean adult (individuals over $2 \mathrm{yr}$ old and $33 \mathrm{~cm}$ whose sex could be visually determined) size that we recorded in the area $\left(L_{\mathrm{s}}=36.29 \pm 0.34 \mathrm{~cm}\right.$; mean $\left.\pm \mathrm{SE}\right)$. For TAS sites, due to much fewer data available, we could not estimate all parameters simultaneously and reliably (evidenced in a lack of convergence and/or stability in the estimates). In particular, we lacked aged individuals older than $3 \mathrm{yr}$, which could result in an underestimation of $L_{\infty}$. We therefore decided to use $3.2 \mathrm{~cm}$ (from Forsgren \& Lowe 2006) as $L_{0}$ value, and to use as $L_{\infty}$ the mean of adult sizes observed in the area $(34.07 \pm 0.39 \mathrm{~cm})$, while estimating the remaining parameters ( $k$ and common birth date). The estimate of $k$ obtained was $0.91 \mathrm{yr}^{-1}\left(95 \% \mathrm{CI}=0.70-1.14 ; \mathrm{r}^{2}\right.$ of the regression $=0.915$ ) (Fig. 5). The estimation that maximizes our fit of the growth curve is that, on average, birth date was January 24.

\section{DISCUSSION}

Weedy seadragons are not only potentially vulnerable and endemic Australian fishes but also fish icons and flagship species for marine conservation. We provide trend data on abundances, and mark-recapture estimates of density, survival and growth based on data collected over a 7 yr period and between locations separated by more than $1000 \mathrm{~km}$. There were clear differences in the demographics among populations of different latitudes. We estimated that southern (TAS) seadragons were born later in the season, had slower growth, and attained a smaller standard length but had higher survival rates and an increased life expectancy compared to those from NSW. 


\section{Temporal and latitudinal demographics}

The present study documents significant declines in the number of weedy seadragons seen in Botany Bay (Sites 1 and 2), an increasingly industrialized bay near Sydney, NSW $\left(34^{\circ} \mathrm{S}\right)$. Abundance, measured as the number of seadragons sighted per area searched, had decreased by 2004 at one site (Site 2) and at both (Sites 1 and 2) by 2007 compared to 2001-2002. There were also significant declines in the number of seadragons seen in 2009 at one of the sites in the lower Derwent estuary (Site 4$)$, near Hobart, TAS $\left(43^{\circ} \mathrm{S}\right)$, about $20 \mathrm{~km}$ from another location where seahorse declines have also been documented (Martin-Smith \& Vincent 2005). The Schnabel and Schumacher-Eschmeyer population size estimates also showed an overall decline from 2001-2002 to 2004 at the 2 Botany Bay sites and in the Derwent estuary. Therefore, 3 out of 5 studied sites showed a decrease in seadragon abundances, as measured by 2 different methods (sightings per area and mark-recapture). This finding raises concerns about the potential threats currently faced by this species.

Several possible hypotheses could explain the population abundance declines for weedy seadragons seen in this study. First, natural interannual fluctuations in recruitment may have occurred and our initial sampling may have been after periods of high recruitment success, such that subsequent declines were due to recruitment failure and natural mortality. In both temperate and tropical regions, the settlement of post-larval fishes has been reported to fluctuate significantly between years (e.g. Shulman 1985, Doherty \& Williams 1988). In seahorses, there is considerable anecdotal evidence of 'boom and bust' cycles and a few population studies documenting these fluctuations (MartinSmith \& Vincent 2005, Freret-Meurer \& Andreata 2008, K. Martin-Smith unpubl. data, D. Harasti pers. comm.).

Alternatively, seadragons may have responded to environmental or habitat changes. Seadragons are highly sensitive to variables such as water quality, temperature and salinity (Koldewey 2005) and have a strong dependence on macroalgal habitats (SanchezCamara et al. 2006). Disease may have been a contributing factor. In NSW, we observed a disease that appeared as erosions or ulcerations of the epidermis that could have had an effect on the populations. For instance, this disease affected $16 \%$ of the seadragons sighted in the Botany Bay area in March to April 2004. Similar lesions causing death have been observed in captive-bred seadragons produced by ciliated parasites (Koldewey 2005, Rossteuscher et al. 2008). Although the effects and causes of this disease were beyond the scope of this work, Botany Bay is an increasingly industrialized area near the northeastern limit of distribution of the species and Australian temperate waters are a hot spot in climate change (Ridgway 2007, Figueira et al. 2009).

Overall, at all sites and time periods, mark-recapture density estimates roughly varied from 10 to 70 seadragons ha ${ }^{-1}$ in NSW, and 15 to 34 seadragons ha-1 in TAS. These densities are 1 to 3 orders of magnitude lower than those reported world-wide for seahorse and pipefish species (Foster \& Vincent 2004, Moreau \& Vincent 2004, Martin-Smith \& Vincent 2005, Curtis \& Vincent 2006). Even the less widespread leafy seadragon Phycodurus eques was reported to occur at a density of 57 individuals ha ${ }^{-1}$ in South Australia (Connolly et al. 2002). In our study, density estimates based in markrecapture data are in general higher than those obtained by direct sightings underwater (compare Table 1 and Fig. 2). We have used the latter variable to analyze trends over time because we have many replicates (surveys) performed in the same way. We do, however, favour the mark-recapture approach for reliable density estimations. While transect measures are sensitive to differences in divers' ability, swimming speed, habitat complexity and other factors that influence sightability, mark-recapture methods, which are based on proportions of tagged vs. untagged animals seen, partition out sightability and survival and allow a more accurate estimation of population size if the appropriate assumptions are met (Arnstrup et al. 2005). Not surprisingly, with this method, abundances are higher that those estimated with direct methods, which do not necessarily detect all animals present.

Adults had high site fidelity over multiple years so it is reasonable to assume that the apparent survival rate $\phi$ is a useful approximation to adult survival rate and that the decrease in re-sightings of marked seadragons observed over years was mostly due to natural death of the ageing cohorts. Apparent survival rates at TAS sites were 9 to $25 \%$ higher than those measured in NSW. Higher survival rates at higher latitudes are a common occurrence in many fish species (Pauly 1980). Annual survival rates were double those found for the seahorse Hippocampus guttulatus (Curtis \& Vincent 2006). The lifespans found in this study range from 6 to over 8 yr and are higher than for most syngnathids (see review by Foster \& Vincent 2004). In captivity, weedy and leafy seadragons live for up to 10 yr (Kuiter 2000, Koldewey 2005). We have some evidence that Tasmanian seadragons $\left(43^{\circ} \mathrm{S}\right)$ have a lifespan that exceed those in Sydney $\left(34^{\circ} \mathrm{S}\right)$ by at least $2 \mathrm{yr}$. This is in accordance with experimental studies on fish that have shown that lowering temperature increases both median and maximum life span (Valenzano et al. 2006).

Many studies have demonstrated that ectotherms, including fish, living in cold, high-latitude environments maintain annual growth rates nearly as high as 
those in warm, low-latitude environments, a phenomenon called latitudinal compensation (Yamahira et al. 2007). In our study, however, seadragons at higher latitudes $\left(43^{\circ} \mathrm{S}\right.$, Hobart) had a lower growth rate than those of warmer waters $\left(34^{\circ} \mathrm{S}\right.$, Sydney). To compare VB curves, the product $L_{\infty} \times k$ is more informative than just the parameter $k$ (Gallucci \& Quinn 1979, Charnov 2010). In our case, the difference in this index is marked and significant (non-overlapping confidence intervals): NSW sites, $L_{\infty} \times k=55.15(95 \% \mathrm{CI}=$ 44.71-66.91); TAS sites, $L_{\infty} \times k=31.02(23.18-39.75)$. Contrary to Bergmann's rule (Bergmann 1847), that proposes a positive correlation between latitude and organism body size, seadragons were larger at lower latitudes. This is the opposite to the pattern observed in the seahorse Hippocampus abdominalis that does follow Bergmann's rule over the same NSW-TAS distance with considerably larger individuals in TAS compared to NSW (height $350 \mathrm{~mm}$ vs. $200 \mathrm{~mm}$, K. Martin-Smith unpubl. data). In a previous study on syngnathids, Bergmann's rule was found to apply to Syngnathus pipefish while no relationship between size and latitude was found for Hippocampus seahorses (Wilson 2009). A study on Syngnathus typhle found that body size varied significantly with latitude but not following a latitudinal gradient (Rispoli \& Wilson 2007). Linking the differences obtained in this study to latitude should be taken with caution, because we have studied seadragons in 2 different study regions only and other factors related to these particular areas studied, e.g. ocean productivity, may of course be relevant.

The growth curve estimated for NSW seadragons differs somewhat from that proposed in SanchezCamara et al. (2005). The higher number of individuals and longer observation times, as well as the high correlation coefficient of the fitted equation with the data, lead us to believe that the new estimates are more accurate. The growth coefficient $k$ is $1.52 \mathrm{yr}^{-1}$, higher than reported previously (1.18 $\mathrm{yr}^{-1}$; op. cit.), which means faster growth during the first months of life. We also estimated a $L_{\infty}$ of $36.28 \mathrm{~cm}$ instead of the $42 \mathrm{~cm}$ previously used. Our estimate of a common birth date was 24 October, close to the 30 October reported in Sanchez-Camara et al. (2005). We have used this common birth date because (1) much more individual data would be necessary to be able to assign a birth date to each aged individual and (2) although the birth period extends from August to December, we have observed most recruits appearing from the peak of brooding males from October to December (Sanchez-Camara et al. 2005). In a study on captive seadragons, Forsgren \& Lowe (2006) suggested a growth equation $\left(L_{0}=3.2 \mathrm{~cm}\right.$, $L_{\infty}=28.50 \mathrm{~cm}, k=2.2$ ) that resulted in sizes similar to those estimated in the present study during the first 6 mo of life. However, that work used a $L_{\infty}$ of $28.5 \mathrm{~cm}$, clearly an underestimation that makes the curve for size-age relationships of older animals unreliable. For TAS, the low number of data points compromises the accuracy of the estimates, but there is a clear indication of slower growth rates, smaller asymptotic sizes, and delayed birth dates (ca. $3 \mathrm{mo}$ ) than in the more northerly study region. Later birth dates in the Southern region were expected because the breeding season of weedy seadragons is delayed (Baker 2000, Woodfield 2002) and the gestation periods are longer (Forsgren \& Lowe 2006) in colder waters.

Information on intermediate localities is necessary to firmly establish the existence of a latitudinal trend. To this end, 7 surveys were conducted in December 2007 in Twofold Bay $\left(37^{\circ} 06^{\prime} 29^{\prime \prime} \mathrm{S}, 149^{\circ} 55^{\prime} 43^{\prime \prime} \mathrm{E}\right)$, Eden, NSW, and 11 seadragons measuring 22 to $28 \mathrm{~cm}\left(L_{\mathrm{s}}\right)$ were found. In that month, settled juveniles observed in TAS were ca. $19 \mathrm{~cm}$, while they were over $30 \mathrm{~cm}$ at the more northerly sites in NSW analyzed in the present study. Therefore, this location at intermediate latitude had intermediate sizes of juveniles, reinforcing the latitudinal trend.

\section{Relevance to species conservation}

Our data represent the first population monitoring of seadragons over ecologically relevant time and space scales. There are clear differences in the reproductive ecology and the growth rates of weedy seadragon populations at different latitudes. Patterns shared among populations that make them vulnerable are: low density, extremely low fecundity, life-time restricted home ranges in a threatened habitat, lack of a dispersive egg phase and low emigration and relocation rates. This is compensated by fast growth and high survival rates and a greater life span compared to most syngnathids (Foster \& Vincent 2004, Curtis \& Vincent 2006).

This work also presents the first evidence of population declines in seadragons. The main concern is whether the declines have natural causes and are temporary, or are due to anthropogenic disturbances. Habitat loss is, after direct exploitation, the main cause of extinction in marine populations, but invasive species, climate change, pollution and disease, are included in the list of potential threats (Dulvy et al. 2003). Kelp forest ecosystems, on which seadragons and their main prey, mysids, depend, are sensitive to climate change, to overfishing (removal of predators that leads to outbreaks of herbivores), and to coastal alteration, including increased construction, runoff, sedimentation, turbidity, and chemical pollution (Poloczanska et al. 2007). Therefore, declines in seadragon populations may be an indicator of a broader ecosystem health problem. Unfortunately, we did not monitor 
changes in the communities (e.g. changes in kelp cover or mysid abundances) during our study, so we cannot link our results directly to particular changes in the habitats. However, over recent years, the habitat of seadragons has been adversely affected by pollution (Connolly 2006) and invasive species (Ling \& Johnson 2009). Significant losses of giant kelp Macrocystis pyrifera have been documented over the past $20 \mathrm{yr}$ in southern Australia (Edyvane 2003), associated with increased water temperatures. Of special concern is how climate change and human activities can affect temperate macroalgal assemblages (Wernberg et al. 2009) on which the seadragons are highly dependent.

The special characteristics of seadragons including small home ranges, low migration and relocation rates, site fidelity and limited movements suggest they may benefit from marine protected areas (MPAs) more than other fish (Kramer \& Chapman 1999). Moreover, as occurs with syngnathids inhabiting seagrass beds (Shokri et al. 2009), the creation of MPAs based on the density of Phyllopteryx taeniolatus might simultaneously benefit other fish.

Acknowledgements. Special thanks to Marlene Davey for her fieldwork conducted in Tasmania during 2003. This project was funded by the Sydney Aquarium Conservation Foundation, The Australian Geographic Society, The PADI Foundation, Guylian Chocolates and Aquadec Aquariums. Required permits were obtained from NSW Fisheries (T01/046, F94/696, P01/044) and NSW Department of Primary Industries (F94/696(A)-4.0). Work was conducted under ethics approval RNSH/UTS Protocol 0106-043A from the University of Technology Sydney/Royal North Shore Hospital Animal Care and under the University of Tasmania's Animal Ethics Project A0007598. We greatly appreciate the helpful comments provided by 3 anonymous reviewers that led to the manuscript's improvement.

\section{LITERATURE CITED}

Arnstrup SC, McDonald TL, Manly BFJ (2005) Handbook of capture-recapture analysis. Princeton University Press, Princeton, NJ

Baker J (2000) New South Wales Dragon Search Project: preliminary bioregional summary of sighting data January 1998-June 2000. Conservation Council of South Australia, Adelaide. Available at: www.reefwatch.asn.au/ dragonsearch/nswnov00/nswnov00.html

Beissinger SR, Westphal MI (1998) On the use of demographic models of population viability in endangered species management. J Wildl Manag 62:821-841

Bergmann C (1847) Über die Verhältnisse der Wärmeökonomie der Thiere zu ihrer Grösse. Göttinger Studien 3:595-708

Burnham KP, Anderson DR, White GC, Brownie C, Polock KH (1987) Design and analysis method for fish survival experiments based on release-recapture. American Fisheries Society, Bethesda, MD

> Caro T, Engilis A Jr, Fitzherbert E, Gardner T (2004) Preliminary assessment of the flagship species concept at a small scale. Anim Conserv 7:63-70

Charnov EL (2010) Comparing body-size growth curves: the Gallucci-Quinn index, and beyond. Environ Biol Fishes 88:293-294

Connolly R (2006) Phyllopteryx taeniolatus. In: IUCN 2009. IUCN Red List of Threatened Species. Version 2009.1. Available at: www.iucnredlist.org/apps/redlist/details/ $17177 / 0$

Connolly RM, Melville AJ, Keesing JK (2002) Abundance, movement and individual identification of leafy seadragons, Phycodurus eques (Pisces: Syngnathidae). Mar Freshw Res 53:777-780

Cooch E, White G (2010) MARK, a gentle introduction, 9th edn. Available at: www.phidot.org/software/mark/docs/ book/

> Curtis JMR, Vincent ACJ (2006) Life history of an unusual marine fish: survival, growth and movement patterns of Hippocampus guttulatus Cuvier 1829. J Fish Biol 68: 707-733

Doherty PJ, Williams DM (1988) The replenishment of coral reef fish populations. Oceanogr Mar Biol Annu Rev 26: $487-551$

Dulvy NK, Sadovy Y, Reynolds JD (2003) Extinction vulnerability in marine populations. Fish Fish 4:25-64

Dulvy NK, Ellis JR, Goodwin NB, Grant A, Reynolds JD, Jennings $S$ (2004) Methods of assessing extinction in marine fishes. Fish Fish 5:255-276

Edgar GJ (2000) Australian marine life. The plants and animals of temperate waters. Reed New Holland, Sydney, p 424-425

Edyvane KS (2003) Conservation, monitoring and recovery of threatened giant kelp (Macrocystis pyrifera) beds in Tasmania - final report. Department of Primary Industries, Water and Environment, Hobart, Tasmania

Figueira WF, Biro P, Booth DJ, Valenzuela VC (2009) Performance of tropical fish recruiting to temperate habitats: role of ambient temperature and implications of climate change. Mar Ecol Prog Ser 384:231-239

> Forsgren KL, Lowe CG (2006) The life history of weedy seadragons, Phyllopteryx taeniolatus (Teleostei: Syngnathidae). Mar Freshw Res 57:313-322

Foster SJ, Vincent ACJ (2004) Life history and ecology of seahorses: implications for conservation and management. J Fish Biol 65:1-61

Freret-Meurer NV, Andreata JV (2008) Field studies of a Brazilian seahorse population, Hippocampus reidi Ginsburg, 1933. Braz Arch Biol Technol 51:743-751

Gallucci VF, Quinn TJ (1979) Reparameterizing, fitting, and testing a simple growth model. Trans Am Fish Soc 108: $14-25$

Hutchings JA (2001) Conservation biology of marine fishes: perceptions and caveats regarding assignment of extinction risk. Can J Fish Aquat Sci 58:108-121

Kendall WL, Nichols JD, Hines JE (1997) Estimating temporary emigration using capture-recapture data with Pollock's robust design. Ecology 78:563-578

> King JR, Mcfarlane GA (2003) Marine fish life history strategies: applications to fisheries management. Fish Manag Ecol 10:249-264

Koldewey H (2005) Syngnathid husbandry in public aquariums. 2005 manual. Project Seahorse, University of British Columbia, Vancouver. Available at: http://seahorse.fisheries. ubc.ca/Documents/Books/Syngnathid_Husbandry_Manual 2005.pdf

> Kramer DL, Chapman MR (1999) Implications of fish home range size and relocation for marine reserve function. Environ Biol Fishes 55:65-79 
Krebs CJ (1999) Ecological methodology, 2nd edn. AddisonWelsey Longman, Menlo Park, CA

Kuiter RH (2000) Seahorses, pipefish and their relatives. A comprehensive guide to Syngnathiformes. TMC Publishing, Chorleywood, p 75-79

Lebreton JD, Burnham KP, Clobert J, Anderson DR (1992) Modelling survival and testing hypothesis using marked animals: a unified approach with case studies. Ecol Monogr 62:67-118

Ling SD, Johnson CR (2009) Population dynamics of an ecologically important range-extender: kelp beds versus sea urchin barrens. Mar Ecol Prog Ser 374:113-125

Ling SD, Johnson CR, Ridgway K, Hobday AJ, Haddon M (2009) Climate-driven range extension of a sea urchin: inferring future trends by analysis of recent population dynamics. Glob Change Biol 15:719-731

Martin-Smith KM, Vincent ACJ (2005) Seahorse declines in the Derwent estuary, Tasmania in the absence of fishing pressure. Biol Conserv 123:533-545

Moreau MA, Vincent ACJ (2004) Social structure and space use in a wild population of the Australian short-headed seahorse Hippocampus breviceps Peters, 1869. Mar Freshw Res 55:231-239

Pauly D (1980) On the interrelationships between mortality, growth parameters, and mean environmental temperature in 175 fish stocks. J Cons 39:175-192

Pogonoski JJ, Pollard DA, Paxton JR (2002) Conservation overview and action plan for threatened and potentially threatened marine and estuarine fishes. Environment Australia, Canberra, p 199-201

Poloczanska ES, Babcock RC, Butler A, Hobday AJ and others (2007) Climate change and Australian marine life. Oceanogr Mar Biol Ann Rev 45:407-478

Potvin C, Roff DA (1993) Distribution-free and robust statistical methods: viable alternatives to parametric statistics. Ecology 74:1617-1628

Ridgway KR (2007) Long-term trend and decadal variability of the southward penetration of the East Australian Current. Geophys Res Lett 34:L13613. doi:10.1029/2007 GL030393

Rispoli VF, Wilson AB (2007) Sexual size dimorphism predicts the frequency of multiple mating in the sex-role reversed pipefish Syngnathus typhle. J Evol Biol 21:30-38

Rossteuscher S, Wenker C, Jermann T, Wahli T, Oldenberg E, Schmidt-Posthaus H (2008) Severe scuticociliate (Philasterides dicentrarchi) infection in a population of sea dragons (Phycodurus eques and Phyllopteryx taeniolatus). Vet Pathol 45:546-550

Sanchez-Camara J, Booth DJ (2004) Movement, home range and site fidelity of the weedy seadragon Phyllopteryx taeniolatus (Teleostei: Syngnathidae). Environ Biol Fishes 70 : $31-41$

Editorial responsibility: Hans Heinrich Janssen, Oldendorf/Luhe, Germany
Sanchez-Camara J, Booth DJ, Turon X (2005) Reproductive cycle and growth of Phyllopteryx taeniolatus. J Fish Biol 67:133-148

Sanchez-Camara J, Booth DJ, Murdoch J, Watts D, Turon X (2006) Density, habitat use and behavior of the weedy seadragon Phyllopteryx taeniolatus (Teleostei: Syngnathidae) around Sydney, New South Wales, Australia. Mar Freshw Res 57:737-745

Shokri MR, Gladstone W, Jelbart J (2009) The effectiveness of seahorses and pipefish (Pisces: Syngnathidae) as a flagship group to evaluate the conservation value of estuarine seagrass beds. Aquat Conserv 19:588-595

Shulman MJ (1985) Recruitment of coral reef fishes: effects of distribution of predators and shelter. Ecology 66: 1056-1066

> Valenzano DR, Terzibasi E, Cattaneo A, Domenici L, Cellerino A (2006) Water temperature modulates lifespan and expression of age-related markers in the shortlived annual fish Nothobranchius furzeri. Aging Cell 5: $275-278$

von Bertalanffy L (1938) A quantitative theory of organic growth (Inquiries on growth laws II). Hum Biol 10:181-213

Wernberg T, Campbell A, Coleman MA, Connell SD and others (2009) Macroalgae and temperate rocky reefs. In: Poloczanska ES, Hobday AJ, Richardson AJ (eds) A Marine Climate Change Impacts and Adaptation Report Card for Australia 2009. National Climate Change Adaptation Research Facility (NCCARF) Publication 05/09, Southport. Available at: www.oceanclimatechange.org.au/ content/images/uploads/Macrolagae.pdf

White GC, Burnham KP (1999) Program MARK: Survival estimation from populations of marked animals. Bird Study 46(Supplement):120-138

White GC, Anderson DR, Burnham KP, Otis DL (1982) Capture-recapture and removal methods for sampling closed populations. Los Alamos National Laboratory, Los Alamos, NM

Wilson AB (2009) Fecundity selection predicts Bergmann's rule in syngnathid fishes. Mol Ecol 18:1263-1272

Woodfield C (2002) Tasmanian Dragon Search Project: bioregional summary of sighting data August 1997-April 2002. Compiled for the Tasmanian Marine Naturalists Association. Conservation Council of South Australia, Adelaide. Available at: www.reefwatch.asn.au/dragonsearch/ tasapr02/tasapr02.htm

Yamahira K, Kawajiri M, Takeshi K, Irie T (2007) Interand intrapopulation variation in thermal reaction norms for growth rate: evolution of latitudinal compensation in ectotherms with a genetic constraint. Evolution 61:1577-1589

Zacharias MA, Roff JC (2001) Use of focal species in marine conservation and management: a review and critique. Aquat Conserv 11:59-76

Submitted: February 15, 2010; Accepted: November 4, 2010 Proofs received from author(s): January 19, 2011 